\title{
2-Arachidonoylglycerol effects in cytotrophoblasts: metabolic enzymes expression and apoptosis in BeWo cells
}

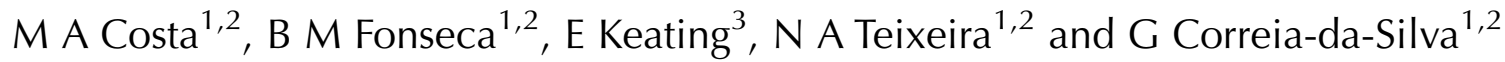 \\ ${ }^{1}$ Laboratório de Bioquímica, Departamento de Ciências Biológicas, Faculdade de Farmácia, Universidade do Porto, \\ Rua de Jorge Viterbo Ferreira n. ${ }^{\circ} 228,4050-313$ Porto, Portugal, ${ }^{2}$ Instituto de Biologia Molecular e Celular da \\ Universidade do Porto (IBMC), Rua do Campo Alegre, 823, 4150-180 Porto, Portugal and ${ }^{3}$ Departmento de \\ Bioquímica, Faculdade de Medicina, Universidade do Porto, Porto, Portugal
}

Correspondence should be addressed to G Correia-da-Silva; Email: george@ff.up.pt

\begin{abstract}
The major endocannabinoid (eCB) 2-arachidonoylglycerol (2-AG) is a member of the endocannabinoid system (ECS) that participates in cell proliferation and apoptosis, important events for the homoeostasis of biological systems. The formation of placenta is one of the most important stages of pregnancy and its development requires highly regulated proliferation, differentiation and apoptosis of trophoblasts. Anomalies in these processes are associated with gestational pathologies. In this work, we aimed to study the involvement of 2-AG in cytotrophoblast cell turnover. We found that 2-AG biosynthetic (diacylglycerol lipase A) and degradative (monoacylglycerol lipase) enzymes are expressed in human cytotrophoblasts and in BeWo cells. We also found that 2-AG induces a decrease in cell viability in a time- and concentration-dependent manner and exerts antiproliferative effects. The loss of cell viability induced by a 48-h treatment with 2-AG $(10 \mu \mathrm{M})$ was accompanied by chromatin fragmentation and condensation, morphological features of apoptosis. Additionally, 2-AG induced an increase in caspase $3 / 7$ and 9 activities, a loss of mitochondrial membrane potential $(\Delta \psi \mathrm{m})$ and an increase in reactive oxygen species (ROS)/reactive nitrogen species (RNS) generation, suggesting the activation of the mitochondrial pathway. Moreover, whereas $\Delta \psi \mathrm{m}$ loss and ROS/RNS generation were significantly attenuated by the antagonists of both the cannabinoid receptors 1 and 2 (CB1 and CB2), the increase in caspase $3 / 7$ and 9 activities and loss of cell viability were reversed only by the antagonist of CB2 receptor; the blockage of the $\mathrm{eCB}$ membrane transporter and the depletion of cholesterol failed to reverse the effects of 2-AG. Therefore, this work supports the importance of cannabinoid signalling during cytotrophoblast cell turnover and that its deregulation may be responsible for altered placental development and poor pregnancy outcomes.

Reproduction (2014) 147 301-311
\end{abstract}

\section{Introduction}

The endocannabinoid system (ECS) is present in several tissues and organs and constitutes a novel target in several physiological and pathophysiological situations. The actual members of the ECS are the two cannabinoid receptors $\mathrm{CB} 1$ and $\mathrm{CB} 2$ and their endogenous ligands (endocannabinoids (eCBs)) and the enzymes involved in the biosynthesis and degradation of eCBs and their putative membrane transporter. There are several endogenous ligands of $\mathrm{CB}$ receptors and anandamide (AEA) and 2-arachidonoylglycerol (2-AG) are considered to be the 'major' eCBs. There are also some other G-protein-coupled receptors that have been described as targets for eCBs (see Fonseca et al. (2013) for a review).

2-AG is synthesized from membrane phospholipids, mainly through a reaction catalysed by diacylglycerol lipase (DAGL) and it is degraded in the cytoplasm into arachidonic acid and glycerol by monoacylglycerol lipase (MAGL). This eCB acts as a full agonist of both
CB1 and CB2 receptors, whereas AEA is only a partial agonist (Pertwee et al. 2010), which leads some authors to defend that 2-AG is the 'true eCB' (Sugiura 2009).

2 -AG has been pointed out as an important messenger in multiple physiological processes in the nervous, immune and cardiovascular systems, though its exact function still remains unclear (Sugiura 2009). It has been reported that this eCB induces apoptosis in some cell types such as decidual cells (Fonseca et al. 2010) and hepatic stellate cells (Siegmund et al. 2007). On the other hand, 2-AG is also involved in pro-proliferative effects in cholangiocarcinoma cells (DeMorrow et al. 2007) and neuroprotection (Chen et al. 2011). The eCBs may play a role in the network of lipids, proteins, cytokines and hormones that regulates the gestational events. Thus, its homoeostasis seems to be crucial for a proper pregnancy outcome. However, little information is available regarding the role of 2-AG in fetalplacental development. In rats, the main metabolic enzymes of 2-AG are expressed in the decidua throughout the gestation, whereas in the placenta they are expressed 
from mid-pregnancy to term pregnancy (Fonseca et al. 2012). Moreover, 2-AG induces apoptosis by the activation of $\mathrm{CB} 1$ receptor, which indicates a role for this $\mathrm{eCB}$ in decidual development and regression (Fonseca et al. 2010). Nevertheless, the involvement of this molecule in human placentation is not clear, though some members of the ECS in this organ have been described. In fact, CB1 and $\mathrm{CB} 2$ receptors and the main metabolic enzymes of AEA, fatty acid amide hydrolase (FAAH) and $\mathrm{N}$-arachidonoylphosphatidylethanolamine-phospholipase D (NAPE-PLD), have been described to be present in first-trimester and term placentas, as well as in BeWo cells (Kenney et al. 1999, Park et al. 2003, Helliwell et al. 2004, Habayeb et al. 2008, Trabucco et al. 2009, Taylor et al. 2011). Furthermore, AEA induces a decrease in the viability of BeWo cells, a cell model of cytotrophoblasts, via CB2 receptor (Habayeb et al. 2008), suggesting a role for the ECS during placentation.

The formation of placenta involves continuous tissue remodelling; apoptosis is a crucial cellular event during this process. In fact, cytotrophoblast cell turnover is very proactive during gestational time: cytotrophoblasts proliferate and differentiate into multinucleated cells named syncytiotrophoblasts, while the quiescent cells die by apoptosis. Alterations in the apoptotic rates during pregnancy have been widely reported to be related to some gestational complications such as pre-eclampsia, intrauterine growth restriction (IUGR) and gestational trophoblastic disease (Smith et al. 1997, Wong et al. 1999, Allaire et al. 2000, Leung et al. 2001, Crocker et al. 2003, Roje et al. 2011). To highlight the role of 2-AG in cytotrophoblast cell turnover occurring during the development of placenta, this work aimed to investigate the expression of the main metabolic enzymes of 2-AG (DAGLA and MAGL) in human cytotrophoblasts and in a cytotrophoblast in vitro cell model as well as the involvement of 2-AG in trophoblast cell proliferation and death. In addition, the signalling pathways activated by this eCB were studied. In these studies, we assessed the presence of 2-AG metabolic enzymes in primary human cytotrophoblasts and in BeWo cells. The choriocarcinoma cell line BeWo was considered a good model for this work, as BeWo cells have the ability to proliferate and produce hormones and proteins similar to human cytotrophoblasts, express CB receptors and other members of the ECS and respond to cannabinoid stimulation (Habayeb et al. 2008). As primary cultures of cytotrophoblasts spontaneously differentiate in vitro into syncytiotrophoblasts (Kliman et al. 1986), the BeWo cell line was used to study the effect of 2-AG on cytotrophoblast cell turnover.

\section{Materials and methods}

\section{Materials}

The human choriocarcinoma cell line BeWo was obtained from the American Type Culture Collection (ATCC, Manassas,
VA, USA). DMEM/F12 medium, fetal bovine serum (FBS), antibiotic-antimycotic solution $(100 \mathrm{U} / \mathrm{ml}$ penicillin $\mathrm{G}$, $100 \mu \mathrm{g} / \mathrm{ml}$ streptomycin and $0.25 \mu \mathrm{g} / \mathrm{ml}$ amphotericin B), $2.5 \%$ trypsin, 3,3'-dihexyloxacarbocyanine iodide $\left(\mathrm{DiOC}_{6}\right.$ ) and TRIzol reagent were from Gibco/Invitrogen Corporation. Rabbit antibodies anti-MAGL, anti-DAGLA and $\beta$-tubulin and rabbit IgG were from Santa Cruz Biotechnology. The peroxidase-conjugated goat anti-rabbit secondary antibody and the Vectastain $A B C$ Rabbit Kit were from Vector Laboratories, Burlingame, CA, USA. Nitrocellulose membranes and Percoll were from GE Healthcare, Chalfont St Giles, Bucks, UK. The Super Signal West Pico Chemiluminescence Detection Kit was from Pierce, Rockford, IL, USA, and X-ray films were from Kodak XAR, Eastman Kodak. DNAse, paraformaldehyde, Sigma Fast Red tablets, Mayer's haematoxylin solution, protease inhibitor cocktail, Triton X-100, methylthiazolyldiphenyl-tetrazolium bromide (MTT), Höechst 33342, methyl- $\beta$-cyclodextrin (MCD), $\mathrm{N}$-acetylcysteine (NAC), staurosporine (STS), carbonyl cyanide m-chlorophenylhydrazone (CCCP), 2,7-dichlorodihydrofluorescein diacetate (DCDHF-DA) and $\mathrm{H}_{2} \mathrm{O}_{2}$ were from Sigma-Aldrich Co. Ethanol, isopropanol and methanol were from Fisher Scientific, Loughborough, UK. DMSO was from VWR, Fontenay-sous-Bois, France. Z-VAD-FMK was from BD PharMingen, San Diego, CA, USA. Aquamount medium was from BDH Laboratory Supplies, Poole, England. The iScript Select cDNA Synthesis Kit and the Experion RNA StdSens Kit were from Bio-Rad Laboratories. The KAPA SYBR FAST qPCR Master Mix $2 \times$ Kit was from Kapa Biosystems, Woburn, MA, USA. 2-AG, AM251, AM630 and AM404 were from Tocris Bioscience, Bristol, UK. CytoTox 96 Non-Radioactive Cytotoxicity Assay Kit, Caspase-Glo 3/7 and Caspase-Glo 9 were from Promega. ${ }^{3} \mathrm{H}$-thymidine was from Amersham. Giemsa was from Merck. Ninety-six-well white plates were from Thermo Scientific, Roskilde, Denmark. Ninety-six-well black plates and eight-well chamber slides were from BD Biosciences, Erembodegem, Belgium. Brains were collected from Wistar rats obtained from Charles River Laboratories, Barcelona, Spain, and all the procedures were conducted in accordance with the guidelines of the Ethics Committee of the Institute of Molecular and Cellular Biology, Porto, Portugal.

\section{Primary cultures of human cytotrophoblasts}

Term placentas of normal pregnancies were immediately collected after spontaneous delivery or elective caesarean section. All the procedures were conducted in accordance with the Ethical Committee of Hospital S. João, Porto. Cytotrophoblast cells were isolated as described previously (Kliman et al. 1986, Keating et al. 2007). Briefly, placentas were washed with saline solution to remove the blood, and villous tissue was dissected and digested in a solution of trypsin and DNAsel. Then, the resulting cells were separated in a discontinuous Percoll gradient. Cytotrophoblasts were collected and seeded in $21 \mathrm{~cm}^{2}$ dishes or eight-well chamber slides at densities $1 \times 10^{7}$ or $4.5 \times 10^{5}$ respectively. The cells were incubated in DMEM/F12 medium supplemented with $10 \%$ (v/v) of FBS and an antibiotic-antimycotic solution at $37^{\circ} \mathrm{C}$ in $95 \%$ air $/ 5 \% \mathrm{CO}_{2}$ humidified atmosphere. After adherence, the cells were washed with PBS and processed as described below. 
The purity of the cytotrophoblast cell culture was assessed by immunocytochemistry with anti-vimentin and anti-cytokeratin antibodies using cells fixed with $4 \%$ paraformaldehyde. Culture was considered pure when $95 \%$ or a higher percentage of cells were cytokeratin positive.

\section{BeWo cell culture}

BeWo cells were maintained in DMEM/F12 medium supplemented with $10 \%(\mathrm{v} / \mathrm{v})$ of FBS and an antibiotic-antimycotic solution and were incubated at $37^{\circ} \mathrm{C}$ in $95 \%$ air $/ 5 \% \mathrm{CO}_{2}$ humidified atmosphere.

\section{Expression of the main metabolic enzymes of 2-AG in human cytotrophoblasts and BeWo cells}

Human cytotrophoblasts and BeWo cells were scraped in RIPA buffer and centrifuged at $14000 \mathrm{~g}$ for $10 \mathrm{~min}$ at $4{ }^{\circ} \mathrm{C}$. Proteins $(100 \mu \mathrm{g})$ were subjected to $10 \%$ SDS-PAGE and transferred onto nitrocellulose membranes. After blocking non-specific binding sites with blocking buffer (5\% of dry milk in PBS with Triton X-1000, 1\%), the membranes were incubated with antiMAGL and anti-DAGLA antibodies (1:100) overnight at $4{ }^{\circ} \mathrm{C}$. Then, the membranes were incubated for $1 \mathrm{~h}$, at room temperature, with peroxidase-conjugated secondary antibody $(1: 1000)$. Finally, the blots were analysed using a chemiluminescence detection kit and exposed to X-ray films. The membranes were then stripped and reincubated with anti- $\beta$ tubulin (1:500) for loading control. A negative control assay was conducted in one strip membrane where the primary antibody was omitted and only the secondary antibody was added to detect non-specific binding (data not shown). Rat brain was used as a positive control.

For immunocytochemistry, human cytotrophoblasts and BeWo cells $\left(3 \times 10^{4}\right.$ cells/well $)$ were seeded in eight-well chamber slides and fixed with methanol, and the expression of DAGLA and MAGL was analysed using an avidin-biotin alkaline phosphatase complex immunohistochemical technique (Vectastain ABC Kit). The non-specific binding sites were blocked and the slides were incubated with anti-DAGLA (1:100) or antiMAGL $(1: 100)$ antibodies overnight at $4{ }^{\circ} \mathrm{C}$. The cells were then incubated with biotinylated secondary antibody, followed by incubation with the Vectastain ABC-AP reagent, according to the manufacturer's instructions. The reaction was developed with Sigma Fast Red tablets. The slides were counterstained with Mayer's haematoxylin solution and mounted in Aquamount medium. Negative control assays were conducted in the absence of primary antibodies, which were replaced with rabbit IgG. Rat brain was used as a positive control.

Gene transcription of MAGL and DAGLA was evaluated by RT-PCR. Human cytotrophoblasts and BeWo cells were collected in TRIzol reagent and total RNA was extracted according to the manufacturer's instructions and quantified in the NanoDrop ND-1000 spectrophotometer (NanoDrop Technologies, Inc., Wilmington, DE, USA). RNA quality was assessed using the Experion RNA StdSens Kit, and the results were analysed with the Experion analytical software (Bio-Rad Laboratories). cDNA was obtained by RT of RNA using the iScript Select cDNA Synthesis Kit. For quantitative PCR, cDNA was amplified using the KAPA SYBR FAST qPCR Master Mix $2 \times$ Kit according to the kit protocol in the MiniOpticon RealTime PCR Detection System (Bio-Rad Laboratories). Primer sequences and PCR conditions are summarized in Table 1. The specificity of the amplified PCR products was assessed by the analysis of the melting curve.

\section{Cell viability}

BeWo cells were plated in 96-well plates at a density of $1 \times 10^{4}$ cells/well. After $24 \mathrm{~h}$, the medium was replaced with DMEM/F12 medium with $1 \%$ FBS and $1 \%$ antibiotic solution in the presence or absence of 2-AG $(0.01-25 \mu \mathrm{M})$, and the cells were incubated for 24,48 and $72 \mathrm{~h}$. The yellow tetrazole MTT (final concentration: $0.5 \mathrm{mg} / \mathrm{ml}$ ) was added, and the cells were incubated for $2 \mathrm{~h} 30 \mathrm{~min}$ at $37^{\circ} \mathrm{C}$. The formed purple formazan was dissolved in a solution of DMSO:isopropanol (3:1) and spectrophotometrically quantified at $540 \mathrm{~nm}$ using a Multiskan Ascent microplate reader. The release of cytoplasmic enzyme lactate dehydrogenase (LDH) into the culture medium was evaluated using the CytoTox 96 Non-Radioactive Cytotoxicity Assay Kit according to the manufacturer's instructions.

\section{Incorporation of ${ }^{3} \mathrm{H}$-thymidine}

Proliferative assays were carried out by the quantification of ${ }^{3} \mathrm{H}$-thymidine incorporated in BeWo cells treated with increasing concentrations of 2 -AG. ${ }^{3} \mathrm{H}$-thymidine (final concentration: $0.5 \mu \mathrm{Ci}$ ) was added $8 \mathrm{~h}$ before the end of the experiment. After two cycles of freezing/defrosting, the cells were harvested using a semi-automated cell harvester (Skatron Instruments, Lier, Norway), $1 \mathrm{ml}$ of scintillation cocktail was added and ${ }^{3} \mathrm{H}$-thymidine that was incorporated was quantified using a scintillation counter (LS 6500, Beckman Instruments, Fullerton, CA, USA).

Table 1 RT-PCR conditions used to assess the gene expression of diacylglycerol lipase A (DAGLA) and monoacylglycerol lipase (MAGL) in BeWo cells.

\begin{tabular}{|c|c|c|c|c|c|c|}
\hline Gene & GenBank & Primer sequence $\left(5^{\prime}-3^{\prime}\right)$ & $\begin{array}{c}\text { Annealing } \\
\text { temperature }\left({ }^{\circ} \mathrm{C}\right)\end{array}$ & $\begin{array}{l}\text { Amplicon } \\
\text { length (bp) }\end{array}$ & $\begin{array}{c}\text { Melting } \\
\text { temperature }\left({ }^{\circ} \mathrm{C}\right)\end{array}$ & Reference \\
\hline$D A G L A$ & NM_006133.2 & $\begin{array}{l}\text { Forward: TGCTCTTCGGCCTGGTCTAT } \\
\text { Reverse: CGCATGCTCAGCCAGATGAT }\end{array}$ & 61 & 130 & 85.6 & $\begin{array}{l}\text { Ludanyi et al. } \\
\text { (2008) }\end{array}$ \\
\hline MAGL & BC000551.2 & $\begin{array}{l}\text { Forward: CAAGGCCCTCATCTTTGTGT } \\
\text { Reverse: ACGTGGAAGTCAGACACTAC }\end{array}$ & 57 & 162 & 85.5 & $\begin{array}{l}\text { Ludanyi et al. } \\
\text { (2008) }\end{array}$ \\
\hline
\end{tabular}




\section{Morphological studies}

2-AG-induced morphological alterations in BeWo cells were evaluated by phase-contrast microscopy and Giemsa and Höechst staining. The cells $\left(3 \times 10^{4}\right)$ were seeded in eightwell chamber slides, treated with 2 -AG $(10 \mu \mathrm{M})$ for $48 \mathrm{~h}$ and fixed with methanol for Giemsa staining or $4 \%$ paraformaldehyde solution for Höechst staining. The cells were incubated with Giemsa stain for $30 \mathrm{~min}$ and analysed under a light microscope or exposed to $0.5 \mathrm{mg} / \mathrm{ml}$ Höechst 33342 (in PBS) for $20 \mathrm{~min}$ and observed under a fluorescence microscope equipped with an excitation filter with maximum transmission at 360/40 nm (Eclipse E400, Nikon, Japan).

\section{Determination of caspase $3 / 7$ and 9 activities}

The cells $\left(5 \times 10^{3}\right)$ were seeded in a 96-well white plate and treated with 2 -AG $(10 \mu \mathrm{M})$ for $36 \mathrm{~h}$, and at the end of the incubation time, Caspase-Glo 3/7 and Caspase-Glo 9 reagents were added to the cells according to the manufacturer's instructions. The plate was incubated at room temperature and the resultant luminescence was measured in relative light luminescence units (RLU) using the 96-well Microplate Luminometer (BioTek Instruments, Winooski, VT, USA). A negative control assay was conducted by co-incubation of 2-AG with a specific caspase inhibitor, Z-VAD-FMK, and a positive control assay was conducted using STS (100 nM), which was added $12 \mathrm{~h}$ before the end of the experiment. The results are expressed in RLU.

\section{Assessment of mitochondrial membrane potential}

BeWo cells were seeded in a 96-well black plate (density $1 \times 10^{4}$ ) and treated with $10 \mu \mathrm{M}$ of 2 -AG for $36 \mathrm{~h}$. The cells were then washed with a PBS/sucrose $100 \mathrm{mM} /$ protease inhibitor (PI) cocktail and incubated with a $100 \mathrm{nM} \mathrm{DiOC}_{6}$ solution for $20 \mathrm{~min}$ at $37^{\circ} \mathrm{C}$ in the dark. The $\mathrm{DiOC}_{6}$ solution was removed to eliminate the background fluorescence, a $\mathrm{PBS} /$ sucrose/PI solution was added to the cells and the fluorescence was read using the Microplate Fluorimeter (BioTek Instruments Winooski, VT, USA) (excitation: $488 \mathrm{~nm}$; emission: $525 \mathrm{~nm}$ ). For the positive control, the cells were incubated with the mitochondrial membrane-depolarizing agent CCCP $(10 \mu \mathrm{M})$ for $15 \mathrm{~min}$, at $37^{\circ} \mathrm{C}$, before incubation with $\mathrm{DiOC}_{6}$. The results are expressed as a percentage, comparing the loss of mitochondrial membrane potential of the 2-AG-treated cells with the untreated cells.

\section{Measurement of intracellular reactive oxygen and nitrogen species}

For the quantification of reactive oxygen species (ROS) and/or reactive nitrogen species (RNS) generated in BeWo cells after a 48-h treatment with 2-AG, cells seeded in a black 96-well plate were incubated with the probe DCDHF-DA for $1 \mathrm{~h}$ at room temperature. Fluorescence was measured using the Microplate Fluorimeter (BioTek Instruments) (excitation: $485 \pm 10 \mathrm{~nm}$; emission: $530 \pm 12.5 \mathrm{~nm}) . \mathrm{H}_{2} \mathrm{O}_{2}(200 \mu \mathrm{M})$ was used as a positive control. The results are expressed as a percentage, comparing the increase in ROS/RNS production induced by 2-AG with the production in the untreated cells.

\section{Signalling pathways involved in 2-AG-induced cell death}

To understand the cellular mechanisms underlying the loss of cell viability and mitochondrial membrane potential, production of ROS/RNS and increase in caspase 3/7 and 9 activities, BeWo cells were pre-exposed to the following compounds: AM251 and AM630 $(1 \mu \mathrm{M})$, antagonists of CB1 and $\mathrm{CB} 2$ receptors respectively; MCD $(400 \mu \mathrm{M})$, a membrane cholesterol-depleting agent; AM404 (1 $\mu \mathrm{M})$, an inhibitor of the putative membrane transporter of eCBs; and NAC (500 $\mu \mathrm{M})$, an antioxidant. For these studies, the cells were pre-treated with $\mathrm{CB}$ antagonists and AM404 for $30 \mathrm{~min}, \mathrm{MCD}$ for $1 \mathrm{~h} 30 \mathrm{~min}$ and NAC was co-incubated with 2-AG. AM251, AM630 and AM404 were dissolved in ethanol; MCD and NAC were dissolved in distilled water. Equimolar concentrations of the vehicles did not induce significant effects on the evaluated parameters (data not shown).

\section{Statistical analysis}

Statistical analysis was carried out using one- or two-way ANOVA, followed by the Bonferroni post hoc test to make pairwise comparisons of individual means when significance was indicated (GraphPad PRISM v. 6.0, GraphPad Software, Inc., San Diego, CA, USA). The results are the mean of at least three independent experiments carried out in triplicate. Data are expressed as the mean \pm S.E.M., and differences were considered to be statistically significant at $P<0.05$.

\section{Results}

\section{Expression of the main enzymes involved in 2-AG biosynthesis and degradation in human cytotrophoblasts and in BeWo cells}

To investigate whether human cytotrophoblast cells possess the enzymatic machinery for 2-AG metabolism, we sought to identify the two key enzymes involved in the biosynthesis and degradation of this eCB, DAGLA and MAGL respectively. Western blot analysis revealed that these enzymes are expressed in primary human cytotrophoblasts (Fig. 1A). Gene transcription of $M A G L$ and DAGLA was investigated by RT-PCR (Fig. 1B). The melting curves indicated that a specific PCR product was amplified in the reactions. Immunocytochemistry revealed a cytosolic expression for both the enzymes (Fig. 1C).

Since we intended to study the role of 2 -AG in cytotrophoblast cell proliferation and apoptosis, we used a cytotrophoblast cell model, due to the spontaneous in vitro differentiation and fusion of human cytotrophoblasts. In this way, we also concluded that the mRNA and protein of both the enzymes are expressed in BeWo cells (Fig. 2A, B and C). 

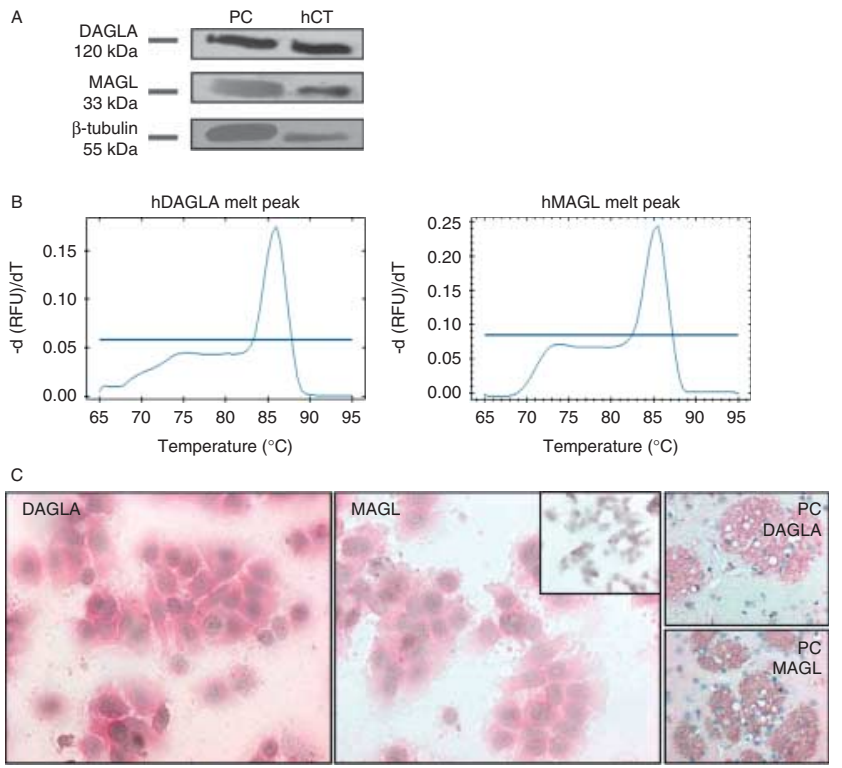

Figure 1 Expression of the main enzymes involved in 2-AG metabolism in human cytotrophoblasts (hCTs). (A) Western blot (WB) analysis revealed that both proteins are expressed in cytotrophoblast cells; $\beta$-tubulin was used as a loading control. (B) RT-PCR revealed that both genes are transcribed, as demonstrated by the specific PCR products represented in the melting curves. (C) Immunocytochemistry (ICC) revealed positive staining for diacylglycerol lipase A (DAGLA) and monoacylglycerol lipase (MAGL). Cells incubated without primary antibody were immunonegative (original magnification $\times 400$ ). Rat brain homogenate and histological sections were used as positive control (PC) for WB and ICC respectively. 2-AG, 2-arachidonoylglycerol.

\section{Effects of 2-AG on BeWo cell viability and proliferation}

The treatment of BeWo cells with 2-AG (10-25 $\mu \mathrm{M})$ induced a decrease in cell viability in a time- and dose-dependent manner (Fig. 3A). After $24 \mathrm{~h}$ of treatment, only the highest concentrations of 2-AG $(25 \mu \mathrm{M})$ caused a significant reduction in cell viability. After 48 and $72 \mathrm{~h}$, a remarkable decrease in cell viability was observed after treatment with 10-25 $\mu \mathrm{M}$ of 2-AG. It was observed that only $25 \mu \mathrm{M}$ or higher concentrations of 2-AG induced the release of LDH (Fig. 3B).

The impact of 2-AG on cell proliferation was studied using the ${ }^{3} \mathrm{H}$-thymidine incorporation assay, after 24 and $48 \mathrm{~h}$ of treatment (Fig. 3C), though a significant reduction in DNA synthesis with $10 \mu \mathrm{M}$ or higher concentrations of 2-AG was observed only after $48 \mathrm{~h}$.

\section{Morphological alterations induced by 2-AG}

The morphological alterations induced by 2-AG in BeWo cells were observed by Giemsa and Höechst staining. Cells treated with 2-AG $(10 \mu \mathrm{M})$ for $48 \mathrm{~h}$ exhibited marked morphological alterations, such as the condensation and fragmentation of chromatin and the presence of apoptotic bodies (Fig. 4), typical features of apoptotic cell death.

\section{Involvement of $C B$ receptors, membrane cholesterol depletion and $\mathrm{eCB}$ membrane transporter in 2-AG-induced cell viability loss}

To understand how 2-AG triggers the decrease in cell viability and morphological alterations in BeWo cells, the cellular signalling pathways that may be involved in these effects were investigated. It was observed that AM630, a selective antagonist of CB2 receptor, partially reversed the decrease in BeWo cell viability, whereas pre-treatment with the selective antagonist of $\mathrm{CB} 1$ receptor, AM251, had no effects (Fig. 5A). The eCBs can enter cells either by the putative $\mathrm{eCB}$ transporter or by simple diffusion. To investigate which mechanisms are involved in 2-AG signalling, BeWo cells were preincubated with AM404, an inhibitor of eCB transporter, or with MCD to deplete membrane cholesterol. Neither the blockage of the putative eCB transporter nor the depletion of cholesterol altered the effect on cell viability induced by 2-AG (10 $\mu \mathrm{M})$ (Fig. 5B).

\section{Induction of apoptosis in BeWo cells by 2-AG via a $C B$ receptor- and mitochondria-dependent mechanism}

As 2-AG-treated cells presented apoptotic features, to further investigate whether the viability loss effects were due to cell death via an apoptotic mechanism, caspase $3 / 7$ and 9 activities and mitochondrial membrane
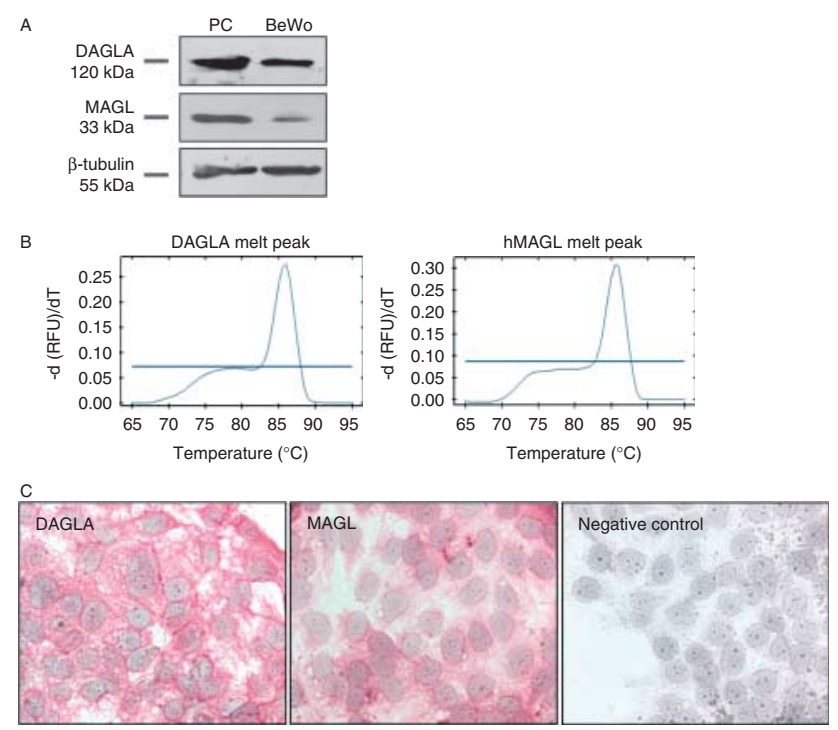

Figure 2 Expression of the main enzymes involved in 2-AG metabolism in BeWo cells. (A) Western blot analysis revealed that both proteins are expressed in BeWo cells; rat brain homogenate was used as positive control (PC) and $\beta$-tubulin was used as a loading control. (B) RT-PCR revealed that both genes are transcribed, as demonstrated by the specific PCR products revealed in the melting curves. (C) Immunocytochemistry revealed positive staining for diacylglycerol lipase A (DAGLA) and monoacylglycerol lipase (MAGL); cells incubated without primary antibody were immunonegative (original magnification $\times 400$ ). 2-AG, 2-arachidonoylglycerol. 

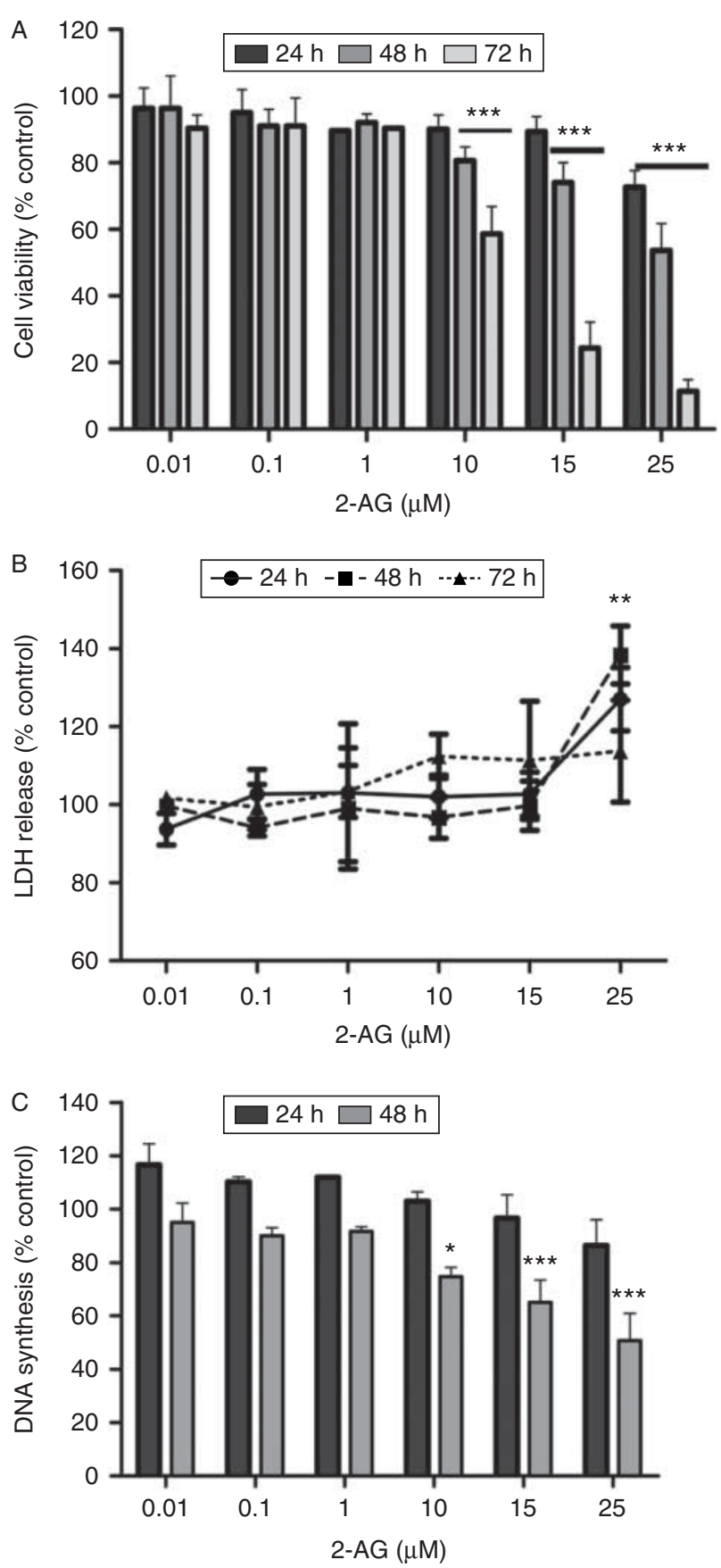

Figure 3 Effects of 2-AG on BeWo cell viability and proliferation, at different times of exposure (24, 48 and 72 h). (A) MTT assay revealed a reduction in cell viability in a time- and concentration-dependent manner (at concentrations higher than $1 \mu \mathrm{M}$ ). This reduction was accompanied by an increase in $\mathrm{LDH}$ release at $25 \mu \mathrm{M}$ (B).

(C) ${ }^{3} \mathrm{H}$-thymidine incorporation decreased, after a 48-h treatment, with $10 \mu \mathrm{M}$ of 2 -AG ${ }^{* * *} P<0.001,{ }^{* *} P<0.01$ and ${ }^{*} P<0.05$ vs control). 2-AG, 2-arachidonoylglycerol; MTT, methylthiazolyldiphenyltetrazolium bromide; LDH, lactate dehydrogenase.

potential $(\Delta \psi \mathrm{m})$ were evaluated. As caspase activation and $\Delta \psi \mathrm{m}$ loss precede cell viability loss, these parameters were evaluated after a shorter incubation time (36 h). As shown in Fig. 6A, 2-AG induced a $\Delta \psi \mathrm{m}$ loss of $23 \%$, compared with that in the control cells, and the antagonists of both the $\mathrm{CB}$ receptors reversed this loss. The mitochondrial membrane-depolarizing agent CCCP induced a $\Delta \psi \mathrm{m}$ loss of $30 \%$. An increase of 20 and $22 \%$ in caspase $3 / 7$ and 9 activities respectively was observed in BeWo cells treated with 2-AG $(10 \mu \mathrm{M})$ for $36 \mathrm{~h}$, in comparison with the control cells (Fig. 6B and $C$ ). The observed increase in caspase $3 / 7$ and 9 activities was significantly reversed only by AM630, antagonist of CB2 receptor.

\section{Induction of the generation of intracellular ROS/RNS by 2-AG}

The generation of ROS and RNS is implicated in several cellular events, including apoptosis. The ability of 2-AG to induce the production of ROS and RNS was assessed by fluorometry with the probe DCDHF-DA. A dramatic increase in the cellular generation of these species, relative to the control cells, was observed. Furthermore, it was verified that the production of ROS and RNS was $\mathrm{CB}$ receptor dependent, as both the antagonists used significantly prevented their generation (Fig. 7A). However, the antioxidant NAC failed to reverse the effects of 2-AG on cell viability (Fig. 7B).

\section{Discussion}

The study of endogenous cannabinoids revealed that cannabinoid signalling plays an important role in several pregnancy events such as embryo implantation, decidualization and labour. Thus, threats to ECS

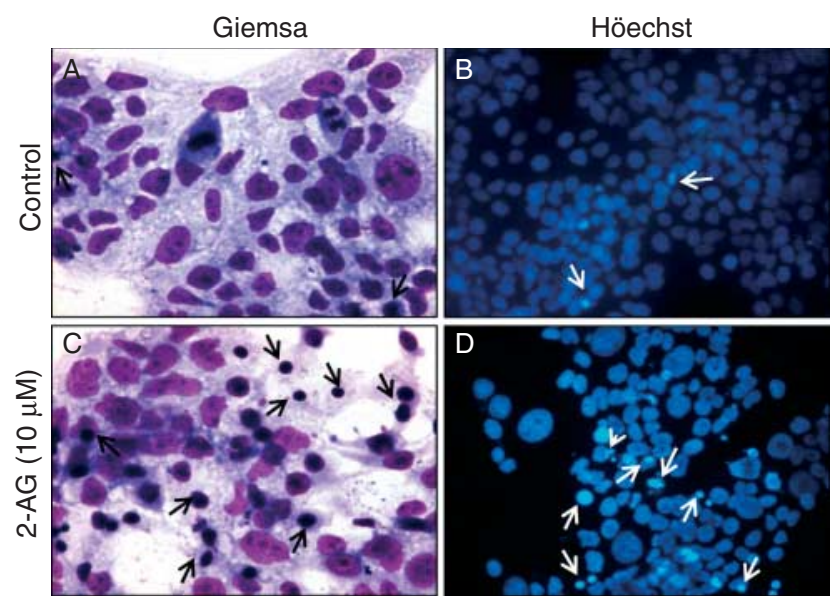

Figure 4 Morphological alterations induced by a 48-h treatment with 2-AG at a concentration of $10 \mu \mathrm{M}$ in BeWo cells. Giemsa staining revealed cell shrinkage and an increase in the number of cells presenting chromatin condensation (arrows) (C) compared with the untreated cells (A). Höechst staining revealed the presence of chromatin condensation and fragmentation and the presence of apoptotic bodies (arrow head) in the treated cells (D), relative to the control cells (B). Original magnification $\times 400(A$ and C) and $\times 200$ (B and D). 2-AG, 2-arachidonoylglycerol. 
A

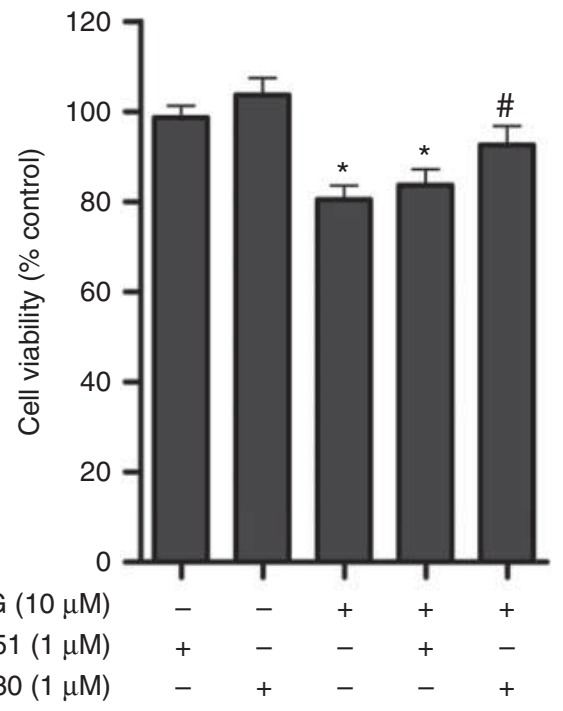

B

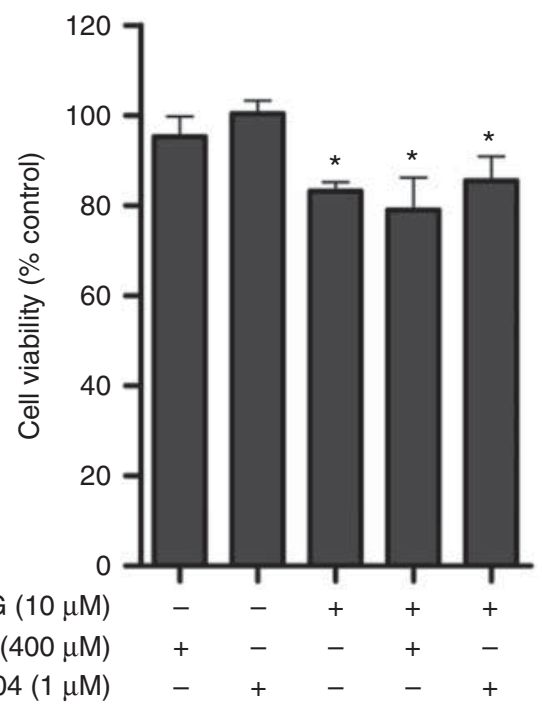

Figure 5 Effects of a 48-h treatment with 2-AG $(10 \mu \mathrm{M})$ in BeWo cells pre-exposed to CB1 antagonist (AM251) and CB2 antagonist (AM630), eCB transporter inhibitor and MCD. (A) The CB2 antagonist partially reversed the decrease in cell viability induced by 2 -AG. AM251 did not exert any effect (A). (B) The blockage of the putative eCB transporter by AM404 and the depletion of membrane cholesterol by MCD did not alter cell viability $\left({ }^{*} P<0.05\right.$ vs control; ${ }^{\sharp} P<0.05$ vs 2 -AG $\left.10 \mu \mathrm{M}\right)$. 2-AG, 2-arachidonoylglycerol; MCD, methyl- $\beta$-cyclodextrin.

homoeostasis are related to infertility and miscarriages (Paria et al. 1996, Wang et al. 2003, Schuel 2006, Fonseca et al. 2010, Taylor et al. 2010). The metabolic enzymes of AEA (NAPE-PLD and FAAH) have already been characterized in human placenta (Kenney et al. 1999, Park et al. 2003, Helliwell et al. 2004, Habayeb et al. 2008, Trabucco et al. 2009, Taylor et al. 2011), and it has also been reported that AEA induces a decrease in BeWo cell viability through the activation of CB2 receptor (Habayeb et al. 2008). On the other hand, only a few studies have examined a possible role for
A

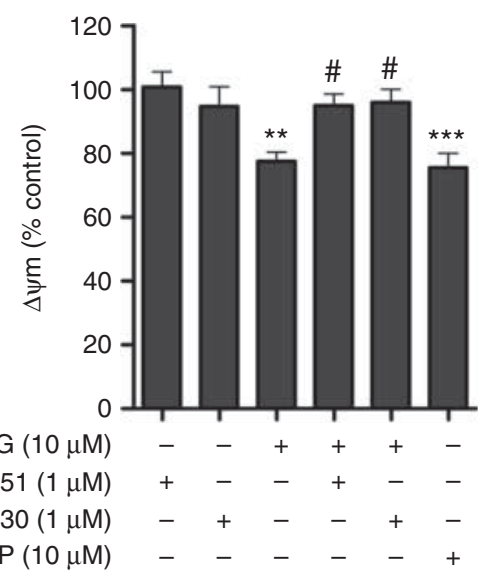

B

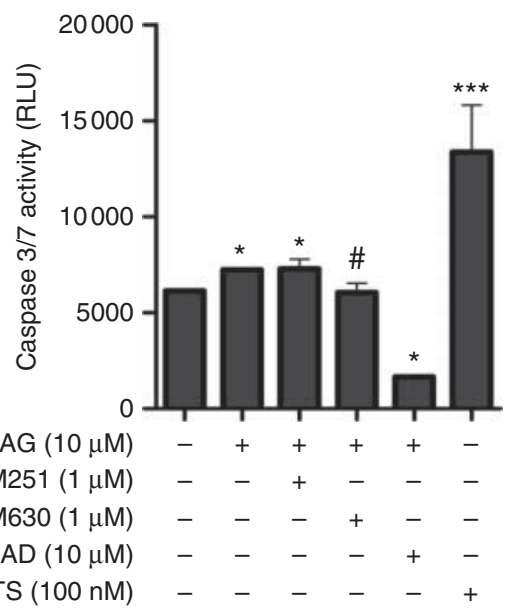

C

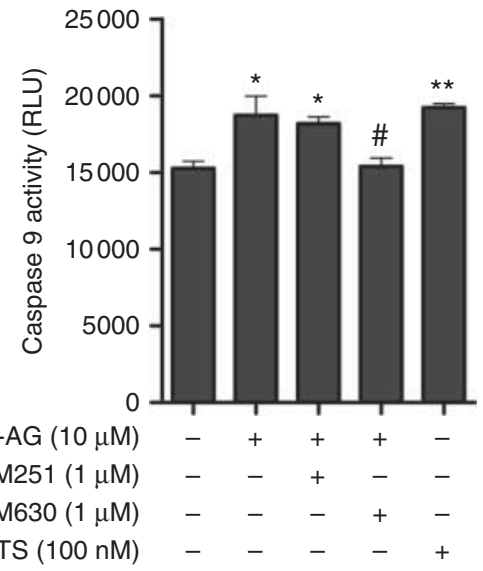

Figure 6 Evaluation of apoptotic markers in BeWo cells treated with 2-AG $(10 \mu \mathrm{M})$ for $36 \mathrm{~h}$. 2-AG induced a loss of mitochondrial membrane potential $(\Delta \psi \mathrm{m})$, which was reversed by the antagonists of both CB1 and CB2 receptors (A). 2-AG induced an increase in caspase $3 / 7$ (B) and 9 (C) activities, compared with that in the untreated cells; this increase was reversed by the CB2 antagonist AM630. STS (100 nM) and Z-VAD-FMK $(10 \mu \mathrm{M})$ were used as positive and negative controls respectively for caspase $3 / 7$ assay $(* * * P<0.001, * * P<0.01$ and ${ }^{*} P<0.05$ vs control; ${ }^{*} P<0.05$ vs 2 -AG $\left.10 \mu \mathrm{M}\right)$. 2 -AG, 2 -arachidonoylglycerol; DiOC6, 3,3'-dihexyloxacarbocyanine iodide; CCCP, carbonyl cyanide m-chlorophenylhydrazone; STS, staurosporine. 

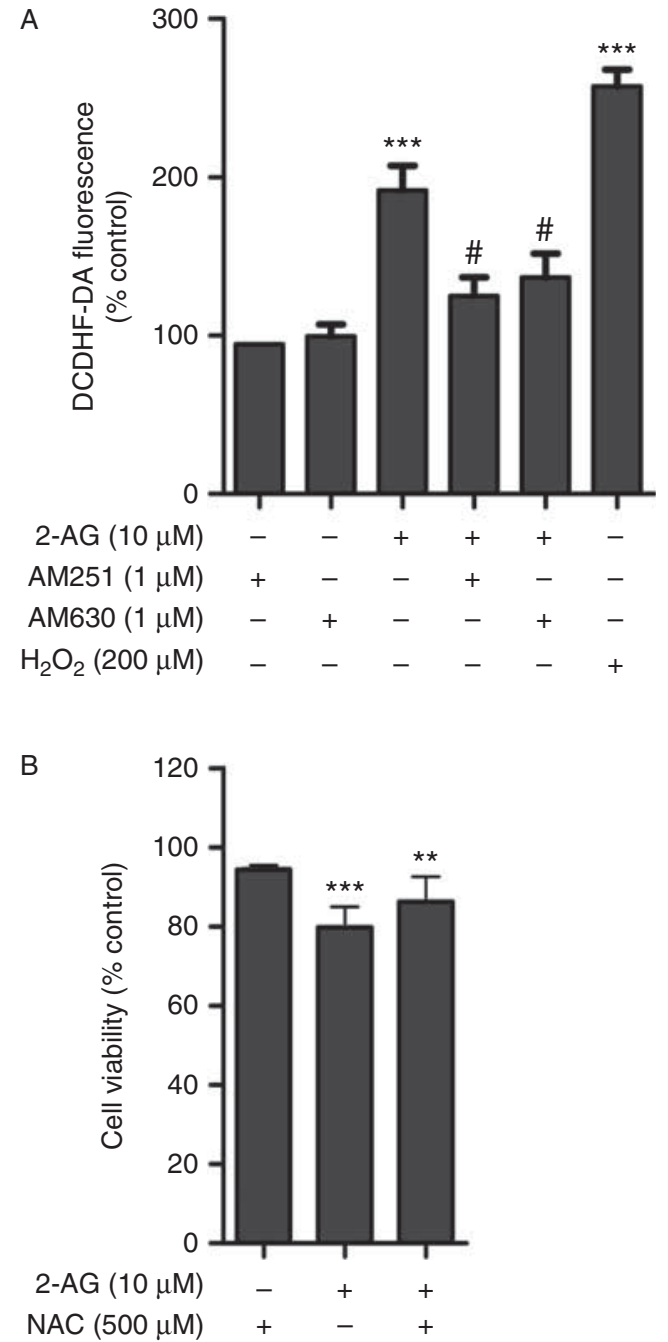

Figure 7 Modulation of ROS/RNS production by $10 \mu \mathrm{M}$ of 2-AG after $48 \mathrm{~h}$ of treatment. 2-AG doubled the generation of ROS/RNS, with this effect being considerably attenuated by the antagonists of both the cannabinoid receptors (A). (B) The antioxidant NAC did not exert any effect on 2-AG-induced decrease in cell viability, suggesting that ROS/RNS generation is not directly involved in cell viability loss $\left({ }^{* * *} P<0.001\right.$ and ${ }^{* *} P<0.01$ vs control; ${ }^{*} P<0.05$ vs 2 -AG $\left.10 \mu \mathrm{M}\right)$. 2-AG, 2-arachidonoylglycerol; DCDHF-DA, 2,7-dichlorodihydrofluorescein diacetate; NAC, N-acetylcysteine.

2-AG in pregnancy. The levels of 2-AG in interimplantation sites of mouse uterus (Wang et al. 2007) and in rat decidual tissue (Fonseca et al. 2010) are respectively 200 - and 150 -fold higher than those of AEA, suggesting that this eCB may be relevant to the regulation of implantation and uterine remodelling. In addition, it is known that 2-AG arrests mouse embryo development via CB1 receptor (Paria et al. 1998) and that the metabolic enzymes of 2-AG in mouse uterus regulate 2-AG during implantation (Wang et al. 2007). In this work, we demonstrate that human cytotrophoblasts and BeWo cells possess the enzymatic tools that regulate 2-AG levels in situ, suggesting that this eCB may be important for cytotrophoblast cell physiology. To our knowledge, this is the first time that 2-AG metabolic machinery is characterized in trophoblast cells. Moreover, the most widely used trophoblast-like cell model, BeWo cells, also expresses these key enzymes of 2-AG metabolism. For this reason and as human cytotrophoblasts spontaneously differentiate to form syncytiotrophoblasts in primary cell culture, not allowing the study of cytotrophoblast cell turnover, BeWo cells were chosen to investigate the effect of 2-AG on cytotrophoblast cell turnover.

The development of placenta is a highly coordinated and regulated event where trophoblast cells proliferate, differentiate and undergo apoptosis. It is well known that anomalies in these cellular processes impair placentation and are implicated in some pregnancy pathologies, such as pre-eclampsia and IUGR (Huppertz et al. 2006). Our results revealed that 2-AG induces a decrease in BeWo cell viability (at concentrations higher than $1 \mu \mathrm{M})$ and also exerts antiproliferative effects, in both a time- and a concentration-dependent manner. The inhibitory action of 2-AG on cell proliferation has already been reported in rat C6 glioma cells (Jacobsson et al. 2001) and colorectal carcinoma cells (Ligresti et al. 2003), both the situations being mediated by CB receptors. Herein, we report that the antiproliferative effects are accompanied by the presence of morphological alterations such as the condensation and fragmentation of chromatin and the presence of apoptotic bodies, typical features of cell death by apoptosis. Moreover, this eCB induced a loss of mitochondrial membrane potential, an increase in caspase 3/7 and 9 activities and an increase in ROS/ RNS production. However, whereas the increase in caspase 3/7 and 9 activities and the loss of cell viability were reversed by the antagonist of CB2 receptor, the other studied parameters were reversed by the antagonists of both the CB receptors. These data suggest that the mitochondrial pathway may be involved in 2-AG-induced apoptosis and that this mechanism is CB receptor dependent. This is in agreement with the data obtained with the inhibition of eCB transporter and alterations in membrane integrity that did not reverse the effects of 2-AG. The inability of AM251 to reverse the increase in caspase 3/7 and 9 activities and loss of cell viability is not totally clarified, and further studies have to be carried out to elucidate the underlying mechanisms that result from the activation of this receptor. However, CB1 receptor is important for the loss of mitochondrial membrane potential and the generation of ROS/RNS, events that precede cell viability loss and may also occur before caspase activation. On the other hand, the activation of CB2 receptor seems to be crucial for the mitochondria-dependent apoptotic stimulus triggered by $2-A G$ in BeWo cells. Although the pro-apoptotic effects of 2-AG have already been described in other cell types, the mechanism may be cell specific. Indeed, 
2-AG induces apoptosis in rat decidual cells by the activation of CB1 receptor (Fonseca et al. 2010) and in hepatic stellate cells through the generation of mitochondrial ROS (Siegmund et al. 2007). Additionally, it has been reported that the other 'major' eCB, AEA, induces a decrease in BeWo cell viability through a mechanism involving CB2 receptor, although the pathways behind this effect have not been totally clarified (Habayeb et al. 2008). These data reinforce a role for the ECS in cytotrophoblast cell turnover and the relevance of the signalling pathways initiated by the activation of CB2 receptor during this process. Besides, 2-AG may be hydrolysed into arachidonic acid, the source of prostaglandins, by MAGL, or metabolized by oxidative enzymes (Fonseca et al. 2013). In addition, as BeWo cells express cyclooxygenase 1 (COX1) and 2 (COX2) (Xu et al. 2005), prostaglandins and 2-AG oxygenated metabolites may be involved in 2-AGmediated cell death, as CB antagonists only partially reverse these effects. Prostaglandins can induce cell death in several cell types (Pignatelli et al. 2005, Huang et al. 2009, Liu et al. 2013), and it is known that the COX2 metabolites of 2-AG, the prostaglandin glyceryl esters, possess biological activity (Nirodi et al. 2004, Sang et al. 2007). Additionally, the COX2 metabolites of AEA, the prostamides, can induce cell death in some cell types (Patsos et al. 2010, Kuc et al. 2012). Further investigation is required to clarify the role of these lipid mediators in cytotrophoblast cell turnover.

During placentation, trophoblasts are in continuous turnover and apoptosis is a key event for the normal formation of the organ, with both extrinsic and intrinsic apoptotic pathways being involved in this cellular event (Heazell \& Crocker 2008). Moreover, members of the Bcl-2 family are differently expressed during the gestational period in cytotrophoblasts and syncytiotrophoblasts (Ishihara et al. 2000, De Falco et al. 2001), with alterations in their expression being described in some pathophysiological situations such as pre-eclampsia, IUGR and hyperglycaemia (Sgarbosa et al. 2006, Tomas et al. 2011, Longtine et al. 2012b, Borzsonyi et al. 2013). Therefore, it seems that anomalies in cell death regulation through the mitochondrial pathway of apoptosis may be involved in pregnancy complications. Also, villous cytotrophoblasts undergo caspase-dependent apoptosis and apoptosis rates in these cells are increased in complicated gestations (Longtine et al. 2012a, 2012b).

Pregnancy is a natural condition of oxidative and nitrative stress. However, greater ROS and/or RNS generation and decreased placental antioxidant defences highly increase the carbonylation and nitration of important proteins and the peroxidation of lipids, altering the biological function of these molecules (Myatt 2010, Burton \& Jauniaux 2011). Moreover, these changes in placental redox state have been reported to be related to some pregnancy complications (Coughlan et al. 2004, Sharma et al. 2006, Biri et al. 2007), and it has been reported that BeWo cell turnover is affected by oxidative stress (Heazell et al. 2009). In this way, considering that 2-AG induces a dramatic increase in the production of ROS and RNS in BeWo cells, the deregulation of cannabinoid signalling may be implicated in alterations of the oxidative state of cytotrophoblasts, interfering with the normal course of gestation.

In conclusion, the existence of the two key enzymes involved in 2-AG biosynthesis and degradation, DAGLA and MAGL, in cytotrophoblast cells allows proper regulation of 2-AG levels in situ. Moreover, the antiproliferative effects and the induction of apoptosis implicate 2-AG in cytotrophoblast cell turnover through the activation of CB2 receptor. Therefore, this eCB may be an important intervener in the development of placenta. Thus, this work highlights the relevance of eCB signalling in placenta, not neglecting that deregulation in ECS homoeostasis may have deleterious effects on cytotrophoblast cell turnover and contribute to the pathophysiological mechanisms of some pregnancy complications.

\section{Declaration of interest}

The authors declare that there is no conflict of interest that could be perceived as prejudicing the impartiality of the research reported.

\section{Funding}

This research did not receive any specific grant from any funding agency in the public, commercial or not-for-profit sector.

\section{Acknowledgements}

The authors thank Fundação para a Ciência e Tecnologia (FCT) for the PhD grant of Mariana Costa (SFRH/BD/70721/2010) and for the post-doctoral grant of Bruno Fonseca (SFRH/BPD/72958/2010) and Obstetrics and Gynaecology Service of Hospital S. João.

\section{References}

Allaire AD, Ballenger KA, Wells SR, McMahon MJ \& Lessey BA 2000 Placental apoptosis in preeclampsia. Obstetrics and Gynecology $\mathbf{9 6}$ 271-276. (doi:10.1016/S0029-7844(00)00895-4)

Biri A, Bozkurt N, Turp A, Kavutcu M, Himmetoglu O \& Durak I 2007 Role of oxidative stress in intrauterine growth restriction. Gynecologic and Obstetric Investigation 64 187-192. (doi:10.1159/000106488)

Borzsonyi B, Demendi C, Rigo J Jr, Szentpeteri I, Rab A \& Joo JG 2013 The regulation of apoptosis in intrauterine growth restriction: a study of $\mathrm{BCl}-2$ and Bax gene expression in human placenta. Journal of Maternal-Fetal \& Neonatal Medicine 26 347-350. (doi:10.3109/14767058.2012.733770)

Burton GJ \& Jauniaux E 2011 Oxidative stress. Best Practice \& Research. Clinical Obstetrics \& Gynaecology 25 287-299. (doi:10.1016/ j.bpobgyn.2010.10.016)

Chen X, Zhang J \& Chen C 2011 Endocannabinoid 2-arachidonoylglycerol protects neurons against $\beta$-amyloid insults. Neuroscience 178 159-168. (doi:10.1016/j.neuroscience.2011.01.024) 
Coughlan MT, Vervaart PP, Permezel M, Georgiou HM \& Rice GE 2004 Altered placental oxidative stress status in gestational diabetes mellitus. Placenta 25 78-84. (doi:10.1016/S0143-4004(03)00183-8)

Crocker IP, Cooper S, Ong SC \& Baker PN 2003 Differences in apoptotic susceptibility of cytotrophoblasts and syncytiotrophoblasts in normal pregnancy to those complicated with preeclampsia and intrauterine growth restriction. American Journal of Pathology 162 637-643. (doi:10.1016/S0002-9440(10)63857-6)

De Falco M, De Luca L, Acanfora F, Cavallotti I, Cottone G, Laforgia V, De Luca B, Baldi A \& De Luca A 2001 Alteration of the Bcl-2:Bax ratio in the placenta as pregnancy proceeds. Histochemical Journal 33 421-425. (doi:10.1023/A:1013728012048)

DeMorrow S, Glaser S, Francis H, Venter J, Vaculin B, Vaculin S \& Alpini G 2007 Opposing actions of endocannabinoids on cholangiocarcinoma growth: recruitment of Fas and Fas ligand to lipid rafts. Journal of Biological Chemistry 282 13098-13113. (doi:10.1074/ jbc.M608238200)

Fonseca BM, Correia-da-Silva G, Taylor AH, Lam PM, Marczylo TH, Bell SC, Konje JC \& Teixeira NA 2010 The endocannabinoid 2-arachidonoylglycerol (2-AG) and metabolizing enzymes during rat fetoplacental development: a role in uterine remodelling. International Journal of Biochemistry \& Cell Biology 42 1884-1892. (doi:10.1016/ j.biocel.2010.08.006)

Fonseca BM, Correia-da-Silva G, Taylor AH, Lam PM, Marczylo TH, Konje JC \& Teixeira NA 2012 Characterisation of the endocannabinoid system in rat haemochorial placenta. Reproductive Toxicology $\mathbf{3 4}$ 347-356. (doi:10.1016/j.reprotox.2012.05.036)

Fonseca BM, Costa MA, Almada M, Correia-da-Silva G \& Teixeira NA 2013 Endogenous cannabinoids revisited: a biochemistry perspective. Prostaglandins \& Other Lipid Mediators 102-103 13-30. (doi:10.1016/ j.prostaglandins.2013.02.002)

Habayeb OM, Taylor AH, Bell SC, Taylor DJ \& Konje JC 2008 Expression of the endocannabinoid system in human first trimester placenta and its role in trophoblast proliferation. Endocrinology 149 5052-5060. (doi:10.1210/en.2007-1799)

Heazell AE \& Crocker IP 2008 Live and let die - regulation of villous trophoblast apoptosis in normal and abnormal pregnancies. Placenta 29 772-783. (doi:10.1016/j.placenta.2008.07.003)

Heazell AE, Taylor NN, Greenwood SL, Baker PN \& Crocker IP 2009 Does altered oxygenation or reactive oxygen species alter cell turnover of BeWo choriocarcinoma cells? Reproductive BioMedicine Online 18 111-119. (doi:10.1016/S1472-6483(10)60432-4)

Helliwell RJ, Chamley LW, Blake-Palmer K, Mitchell MD, Wu J, Kearn CS \& Glass M 2004 Characterization of the endocannabinoid system in early human pregnancy. Journal of Clinical Endocrinology and Metabolism 89 5168-5174. (doi:10.1210/jc.2004-0388)

Huang SK, White ES, Wettlaufer SH, Grifka H, Hogaboam CM, Thannickal VJ, Horowitz JC \& Peters-Golden M 2009 Prostaglandin $\mathrm{E}(2)$ induces fibroblast apoptosis by modulating multiple survival pathways. FASEB Journal 23 4317-4326. (doi:10.1096/fj.08-128801)

Huppertz B, Kadyrov M \& Kingdom JC 2006 Apoptosis and its role in the trophoblast. American Journal of Obstetrics and Gynecology 195 29-39. (doi:10.1016/j.ajog.2005.07.039)

Ishihara N, Matsuo H, Murakoshi H, Laoag-Fernandez J, Samoto T \& Maruo T 2000 Changes in proliferative potential, apoptosis and Bcl-2 protein expression in cytotrophoblasts and syncytiotrophoblast in human placenta over the course of pregnancy. Endocrine Journal 47 317-327. (doi:10.1507/endocrj.47.317)

Jacobsson SO, Wallin T \& Fowler CJ 2001 Inhibition of rat C6 glioma cell proliferation by endogenous and synthetic cannabinoids. Relative involvement of cannabinoid and vanilloid receptors. Journal of Pharmacology and Experimental Therapeutics 299 951-959.

Keating E, Goncalves P, Lemos C, Costa F, Campos I, Smith SB, Bridges CC \& Martel F 2007 Progesterone inhibits folic acid transport in human trophoblasts. Journal of Membrane Biology 216 143-152. (doi:10.1007/ s00232-007-9057-5)

Kenney SP, Kekuda R, Prasad PD, Leibach FH, Devoe LD \& Ganapathy V 1999 Cannabinoid receptors and their role in the regulation of the serotonin transporter in human placenta. American Journal of Obstetrics and Gynecology 181 491-497. (doi:10.1016/S00029378(99)70583-1)
Kliman HJ, Nestler JE, Sermasi E, Sanger JM \& Strauss JF III 1986 Purification, characterization, and in vitro differentiation of cytotrophoblasts from human term placentae. Endocrinology 118 1567-1582. (doi:10.1210/endo-118-4-1567)

Kuc C, Jenkins A \& Van Dross RT 2012 Arachidonoyl ethanolamide (AEA)-induced apoptosis is mediated by J-series prostaglandins and is enhanced by fatty acid amide hydrolase (FAAH) blockade. Molecular Carcinogenesis 51 139-149. (doi:10.1002/mc.20770)

Leung DN, Smith SC, To KF, Sahota DS \& Baker PN 2001 Increased placental apoptosis in pregnancies complicated by preeclampsia. American Journal of Obstetrics and Gynecology 184 1249-1250. (doi:10.1067/mob.2001.112906)

Ligresti A, Bisogno T, Matias I, De Petrocellis L, Cascio MG, Cosenza V, D'Argenio G, Scaglione G, Bifulco M, Sorrentini I et al. 2003 Possible endocannabinoid control of colorectal cancer growth. Gastroenterology 125 677-687. (doi:10.1016/S0016-5085(03)00881-3)

Liu H, Li W, Rose ME, Pascoe JL, Miller TM, Ahmad M, Poloyac SM, Hickey RW \& Graham SH 2013 Prostaglandin D toxicity in primary neurons is mediated through its bioactive cyclopentenone metabolites. Neurotoxicology 39C 35-44. (doi:10.1016/j.neuro.2013.08.001)

Longtine MS, Chen B, Odibo AO, Zhong Y \& Nelson DM 2012a Caspasemediated apoptosis of trophoblasts in term human placental villi is restricted to cytotrophoblasts and absent from the multinucleated syncytiotrophoblast. Reproduction 143 107-121. (doi:10.1530/REP-11-0340)

Longtine MS, Chen B, Odibo AO, Zhong Y \& Nelson DM 2012b Villous trophoblast apoptosis is elevated and restricted to cytotrophoblasts in pregnancies complicated by preeclampsia, IUGR, or preeclampsia with IUGR. Placenta 33 352-359. (doi:10.1016/j.placenta.2012.01.017)

Myatt L 2010 Review: reactive oxygen and nitrogen species and functional adaptation of the placenta. Placenta 31 (Suppl) S66-S69. (doi:10.1016/ j.placenta.2009.12.021)

Nirodi CS, Crews BC, Kozak KR, Morrow JD \& Marnett LJ 2004 The glyceryl ester of prostaglandin $\mathrm{E}_{2}$ mobilizes calcium and activates signal transduction in RAW264.7 cells. PNAS 101 1840-1845. (doi:10.1073/ pnas.0303950101)

Paria BC, Deutsch DD \& Dey SK 1996 The uterus is a potential site for anandamide synthesis and hydrolysis: differential profiles of anandamide synthase and hydrolase activities in the mouse uterus during the periimplantation period. Molecular Reproduction and Development 45 183-192. (doi:10.1002/(SICl)1098-2795(199610) 45:2<183::AID-MRD11> 3.0.CO;2-2)

Paria BC, Ma W, Andrenyak DM, Schmid PC, Schmid HH, Moody DE, Deng H, Makriyannis A \& Dey SK 1998 Effects of cannabinoids on preimplantation mouse embryo development and implantation are mediated by brain-type cannabinoid receptors. Biology of Reproduction 58 1490-1495. (doi:10.1095/biolreprod58.6.1490)

Park B, Gibbons HM, Mitchell MD \& Glassa M 2003 Identification of the CB1 cannabinoid receptor and fatty acid amide hydrolase (FAAH) in the human placenta. Placenta 24 473-478. (doi:10.1053/plac.2002.0926)

Patsos HA, Greenhough A, Hicks DJ, AI Kharusi M, Collard TJ, Lane JD, Paraskeva C \& Williams AC 2010 The endogenous cannabinoid, anandamide, induces COX-2-dependent cell death in apoptosis-resistant colon cancer cells. International Journal of Oncology 37 187-193. (doi:10.3892/ijo_00000666)

Pertwee RG, Howlett AC, Abood ME, Alexander SP, Di Marzo V, Elphick MR, Greasley PJ, Hansen HS, Kunos G, Mackie K et al. 2010 International Union of Basic and Clinical Pharmacology. LXXIX. Cannabinoid receptors and their ligands: beyond $\mathrm{CB}_{1}$ and $\mathrm{CB}_{2}$. Pharmacological Reviews 62 588-631. (doi:10.1124/pr.110.003004)

Pignatelli M, Sanchez-Rodriguez J, Santos A \& Perez-Castillo A 2005 15deoxy-Delta-12,14-prostaglandin $\mathrm{J} 2$ induces programmed cell death of breast cancer cells by a pleiotropic mechanism. Carcinogenesis 26 81-92. (doi:10.1093/carcin/bgh308)

Roje D, Tomas SZ, Prusac IK, Capkun V \& Tadin I 2011 Trophoblast apoptosis in human term placentas from pregnancies complicated with idiopathic intrauterine growth retardation. Journal of Maternal-Fetal \& Neonatal Medicine 24 745-751. (doi:10.3109/14767058.2010.526158)

Sang N, Zhang J \& Chen C 2007 COX-2 oxidative metabolite of endocannabinoid 2-AG enhances excitatory glutamatergic synaptic transmission and induces neurotoxicity. Journal of Neurochemistry 102 1966-1977. (doi:10.1111/j.1471-4159.2007.04668.x)

Schuel H 2006 Tuning the oviduct to the anandamide tone. Journal of Clinical Investigation 116 2087-2090. (doi:10.1172/JCI29424) 
Sgarbosa F, Barbisan LF, Brasil MA, Costa E, Calderon IM, Goncalves CR Bevilacqua E \& Rudge MV 2006 Changes in apoptosis and Bcl-2 expression in human hyperglycemic, term placental trophoblast. Diabetes Research and Clinical Practice 73 143-149. (doi:10.1016/ j.diabres.2005.12.014)

Sharma JB, Sharma A, Bahadur A, Vimala N, Satyam A \& Mittal S 2006 Oxidative stress markers and antioxidant levels in normal pregnancy and pre-eclampsia. International Journal of Gynaecology and Obstetrics 94 23-27. (doi:10.1016/j.ijgo.2006.03.025)

Siegmund SV, Qian T, de Minicis S, Harvey-White J, Kunos G, Vinod KY Hungund B \& Schwabe RF 2007 The endocannabinoid 2-arachidonoyl glycerol induces death of hepatic stellate cells via mitochondrial reactive oxygen species. FASEB Journal 21 2798-2806. (doi:10.1096/ fj.06-7717com)

Smith SC, Baker PN \& Symonds EM 1997 Increased placental apoptosis in intrauterine growth restriction. American Journal of Obstetrics and Gynecology 177 1395-1401. (doi:10.1016/S0002-9378(97)70081-4)

Sugiura T 2009 Physiological roles of 2-arachidonoylglycerol, an endogenous cannabinoid receptor ligand. Biofactors 35 88-97. (doi:10.1002/ biof.18)

Taylor AH, Amoako AA, Bambang K, Karasu T, Gebeh A, Lam PM, Marzcylo TH \& Konje JC 2010 Endocannabinoids and pregnancy. Clinica Chimica Acta 411 921-930. (doi:10.1016/j.cca.2010.03.012)

Taylor AH, Finney M, Lam PM \& Konje JC 2011 Modulation of the endocannabinoid system in viable and non-viable first trimester pregnancies by pregnancy-related hormones. Reproduction Biology and Endocrinology 9 152. (doi:10.1186/1477-7827-9-152)

Tomas SZ, Prusac IK, Roje D \& Tadin I 2011 Trophoblast apoptosis in placentas from pregnancies complicated by preeclampsia. Gynecologic and Obstetric Investigation 71 250-255. (doi:10.1159/000320289)
Trabucco E, Acone G, Marenna A, Pierantoni R, Cacciola G, Chioccarelli T, Mackie K, Fasano S, Colacurci N, Meccariello R et al. 2009 Endocannabinoid system in first trimester placenta: low FAAH and high CB1 expression characterize spontaneous miscarriage. Placenta 30 516-522. (doi:10.1016/j.placenta.2009.03.015)

Wang H, Matsumoto H, Guo Y, Paria BC, Roberts RL \& Dey SK 2003 Differential G protein-coupled cannabinoid receptor signaling by anandamide directs blastocyst activation for implantation. PNAS 100 14914-14919. (doi:10.1073/pnas.2436379100)

Wang H, Xie H, Sun X, Kingsley PJ, Marnett LJ, Cravatt BF \& Dey SK 2007 Differential regulation of endocannabinoid synthesis and degradation in the uterus during embryo implantation. Prostaglandins \& Other Lipid Mediators 83 62-74. (doi:10.1016/j.prostaglandins. 2006.09.009)

Wong SY, Ngan HY, Chan CC \& Cheung AN 1999 Apoptosis in gestational trophoblastic disease is correlated with clinical outcome and Bcl-2 expression but not Bax expression. Modern Pathology 12 1025-1033.

Xu Y, Knipp GT \& Cook TJ 2005 Expression of cyclooxygenase isoforms in developing rat placenta, human term placenta, and BeWo human trophoblast model. Molecular Pharmaceutics 2 481-490. (doi:10.1021/ mp0500519)

Received 4 November 2013

First decision 25 November 2013

Revised manuscript received 29 November 2013

Accepted 9 December 2013 